\title{
Challenges to Make Salmon in Sanriku an Icon of the Region
}

\author{
Jun Aoyama and Susumu Hyodo \\ International Coastal Research Center, Atmosphere and Ocean Research Institute, The University of Tokyo, \\ Akahama 1-19-8, Otsuchi, Iwate 028-1102, Japan
}

Keywords: recovery from the Great East Japan earthquake, Sanriku, chum salmon, local identity

Hokkaido and Iwate are major areas for salmon production in Japan as these regions have accounted for about $80 \%$ (Hokkaido) and 10-15\% (Iwate) of total chum salmon annual catch in Japanese coastal waters (except recent years); Hokkaido has provided nearly $55 \%$ of chum juveniles for the stock enhancement program, while Iwate has provided 25\%. The Great East Japan earthquake on 11 March 2011, struck off the northeastern coast of Japan causing a massive tsunami that severely damaged the Pacific coast of the Tohoku region. The coastal devastation was much more extensive in Iwate (the Sanriku region) where it is geographically characterized as a Ria - a deeply embayed coast with steadily increasing depth seaward - making the tsunami higher than in other areas. Important facilities for the salmon fishery, including hatcheries and processing plants as well as natural habitats for salmon, were destroyed or severely damaged by the tsunami. As part of the Tohoku Ecosystem-Associated Marine Sciences Program (TEAMS), subsidized by the Ministry of Education, Culture, Sports, Science and Technology (MEXT) and Atmosphere and Ocean Research Institute, the University of Tokyo launched a project named "Project Grand Maillet" (PGM) to ascertain the impacts of the tsunami on the coastal ecosystem and to observe subsequent environmental or ecological transitions. This project involved research on salmon to help the reconstruction of fishery industries in the region affected by the disaster. Studies conducted by the project have revealed many specific ecological/physiological traits of salmon in Sanriku, presumably due to its particular environment for salmon reproduction; Sanriku has relatively warm water in rivers during the winter because of its latitude and oceanographic conditions and rich spring waters affect water composition (e.g., Aoyama 2017; Kitagawa et al. 2017; Abe et al. 2019; Nobata et al. 2019). These findings potentially provide a new insight into the stock enhancement techniques adapted to the local environment of Sanriku. However, the economic importance of salmon, which accounted for more than $20 \%$ of the total fishery production in Iwate in 2006 , has declined sharply, to only about 6\% in 2019 (Iwate Prefecture 2020). Furthermore, the number of fishery workers in the region has also been declining, particularly after the disaster (Iwate Prefecture 2020). These facts imply that an intensive salmon fishery approach for regional reconstruction contribute less to the whole local community and a much broader and more inclusive approach is required. The PGM has initiated a multidisciplinary approach to know the actual status of salmon in Sanriku to re-establish ecological, cultural, and commercial images of salmon in Japan, which has mostly relied on Hokkaido. A variety of studies conducted in the project revealed not only locally specific ecological characteristics, but also anthropological traits such as traditions or relationships between humans and salmon in Sanriku (e.g., Yoshimura and Aoyama 2019) which are different from the indigenous Ainu culture described from Hokkaido. These facts suggest that the salmon in Sanriku have ecologically adapted to the local environment and have established a long and good relationship with people in the area. The salmon in Sanriku are not only a fishery resource but could potentially be an icon of the region or a local identity that encourages the reconstruction of society from the disaster.

\section{REFERENCES}

Abe, T.K., T. Kitagawa, Y. Makiguchi, and K. Sato. 2019. Chum salmon migrating upriver adjust to environmental temperatures through metabolic compensation. J. Exp. Biol. 222: jeb186189.

Aoyama, J. 2017. Natural spawning of chum salmon Oncorhynchus keta within a hatchery stock enhancement program - a case in the Otsuchi River at the Sanriku coast. Coast. Mar. Sci. 40: 1-6.

Iwate Prefecture. 2020. Indicators for Iwate Prefectural Fisheries. (Available at https://www.pref.iwate.jp/res/projects/default_project/page/001/040/881/hp/10zentai.pdf) (In Japanese)

Kitagawa, T., T. Kawakami, S. Nobata, Y. Minegishi, M. Ito, T. Otake, J. Aoyama, and S. Hyodo. 2017. Influences on ecology of diadromous fish species by the massive tsunami with the mega-earthquake. Nippon Suisan Gakkaishi 83: 681-684. (In Japanese)

Nobata, S., T. Kitagawa, K. Tanaka, K. Komatsu, Y. Aoki, K. Sato, Y. Takei, S. Hyodo. 2019. Spreading of river water guides migratory behavior of homing chum salmon Oncorhynchus keta in Otsuchi Bay, a narrow inlet with multiple river flows. Zool. Sci. 36: 449-457.

All correspondence should be addressed to J. Aoyama.

email: jaoyama@aori.u-tokyo.ac.jp 
Yoshimura, K., and J. Aoyama. 2019. Social function of the salmon in Sanriku area from the viewpoint of historical transitions in the distribution. Chiiki Gyogyou Kenkyu 59: 138-145. (In Japanese with English abstract) 